\title{
Reply to Letter to the Editor
}

\section{Use of Morphometry to Quantify Osteolysis after Total Hip Arthroplasty}

\author{
L. K. Smith MSc
}

Published online: 2 December 2010

(C) The Association of Bone and Joint Surgeons( 2010

I thank Dr. Mehin for his comments regarding our paper [2] describing the use of a morphometric grid to quantify osteolysis seen on radiographs.

I agree with him regarding the importance of the location and size of retroacetabular osteolytic lesions in the assessment of a THA. The availability of a simple and reliable tool to quantify these lesions is important for long-term THA surveillance and also can be useful to explain to asymptomatic patients the significance of radiographic changes.

Further research with the morphometric grid may help to describe the extent of osteolysis, which predicts instability of an acetabular component. This, along with other work including that of Dr. Mehin and his colleagues [1], will contribute to the decision-making process for revision hip surgery.

\section{References}

1. Mehin R, Yuan X, Haydon C, Rorabeck CH, Bourne RB, McCalden RW, MacDonald SJ. Retroacetabular osteolysis: when to operate? Clin Orthop Relat Res. 2004;428:247-255.

2. Smith LK, Cramp F, Palmer S, Coghill N, Spencer RF. Use of morphometry to quantify osteolysis after total hip arthroplasty. Clin Orthop Relat Res. 2010;468:3077-3083.
(Re: Smith LK, Cramp F, Palmer S, Coghill N, Spencer RF. Use of morphometry to quantify osteolysis after total hip arthroplasty. Clin Orthop Relat Res. 2010;468:3077-3083.)

\section{K. Smith $(\square)$}

Department of Trauma and Orthopaedic Surgery,

Weston General Hospital, Grange Road, Uphill,

Weston-s-Mare BS23 4TQ, England, UK

e-mail: smith@unforgettable.com 